\title{
A escola tem que discutir; a família que deve orientar: as escolas rio-grandinas e as questões de gênero
}

\section{RESUMO}

$\mathrm{O}$ presente estudo se propôs a averiguar o tratamento dado a temática gênero em escolas da cidade de Rio Grande - RS, assim como, identificar o posicionamento dos professores e professoras sobre a temática gênero ser trabalhada nessas instituições. Os sujeitos participantes dessa pesquisa foram professores e professoras de Educação Física e alunos e alunas do $9^{\circ}$ ano do ensino fundamental, os quais contribuíram, respectivamente, através dos seguintes instrumentos de coleta: entrevista semiestruturada e questionário. Percebemos que a instituição escola não é um campo neutro, pois ela ainda é um espaço que internaliza os preceitos que estruturam a sociedade, reforçando binarismos. Identificamos que às questões que envolvem gênero não são uma temática muito recorrente nas escolas investigadas, sendo que os professores e as professoras têm distintas percepções sobre essa ser tratada nas escolas e nas aulas de Educação Física, resultando em dois grupos: os pró-discussão (acreditam que essa temática é pertinente de discussão no âmbito escolar, buscando a transformação radical do contexto social) e os contra discussão (não apresentam interesse nessa discussão, não abrindo espaço para o debate, revelando o quão interessado está na manutenção da ordem social da lógica do sistema de dominação-exploração).

PALAVRAS-CHAVE: Questões de gênero;

Sociedade; Escola
Thais Mortola Dias

Mestra em Educação Física Universidade Federal de Pelotas, Programa de Pós-Graduação em Educação Física, Pelotas,

Rio Grande do Sul, Brasil. thais-mortola@hotmail.com (1) https://orcid.org/0000-0003-2642-7013

Giovanni Felipe Ernst Frizzo

Doutor em Ciências do Movimento Humano Universidade Federal de Pelotas, Programa de Pós-Graduação em Educação Física, Pelotas,

Rio Grande do Sul, Brasil. gfrizzo2@gmail.com

(1) https://orcid.org/0000-0003-0025-9947 
The school has to argue; the family to guide: rio-grandinas schools and gender issues

\begin{abstract}
The present study aims to investigate the treatment given to gender in schools in the city of Rio Grande - RS, as well as to identify the position of male and female teachers on the subject of gender to be worked on in these institutions. The participants participating in this research were teachers and Physical Education teachers and 9th grade students, who contributed, respectively, through the collection instruments: semi-structured interview and questionnaire. We realize that the school institution is not a neutral field, as it is still a space that internalizes the precepts that structure society, reinforcing binarisms. We identified that gender issues are not a very recurring theme in the investigated schools, and teachers have different perceptions about this being addressed in schools and in Physical Education classes, concluded in two groups: the pro-discussion (believing that this theme is pertinent to the discussion in the school context, seeking a radical transformation of the social context) and the counter-arguments (they are not interested in this discussion, not opening the space for the debate, revealing the interest of the interest is in maintaining order of the logic of the domination-exploitation system).
\end{abstract}

KEYWORDS: Gender issues; Society; School

La escuela tiene que discutir; la familia para guiar: las escuelas rio-grandinas y las cuestiones de género

\title{
RESUMEN
}

El presente estudio se propone investigar el tratamiento que se le da al género en las escuelas de la ciudad de Rio Grande - RS, así como identificar la posición de docentes y maestras en la temática de género a trabajar en estas instituciones. Los participantes que participaron en esta investigación fueron profesores y profesores de Educación Física y estudiantes de $9^{\circ}$ grado, quienes contribuyeron, respectivamente, a través de los instrumentos de recolección: entrevista semiestructurada y cuestionario. Nos damos cuenta de que la institución escolar no es un campo neutral, pues sigue siendo un espacio que interioriza los preceptos que estructuran la sociedad, reforzando los binarismos. Identificamos que la problemática de género no es un tema muy recurrente en las escuelas investigadas, y los docentes tienen diferentes percepciones sobre esto siendo abordado en las escuelas y en las clases de Educación Física, concluido en dos grupos: el pro-discusión (creyendo que este tema es pertinente para la discusión en el contexto escolar, buscando una transformación radical del contexto social) y los contraargumentos (no les interesa esta discusión, no abren el espacio para el debate, revelan que el interés de interés es mantener el orden de la lógica del sistema de dominación-explotación).

PALABRAS-CLAVE: Cuestiones de género; Sociedad; Escuela 


\section{INTRODUÇÃO}

Para além do rosa e azul. Para além das "coisas de menino" e "coisas de menina". Para além do "as coisas são assim mesmo". Permeado de construção social, cultural e histórica, o termo gênero agrega em si características ditas pertencentes e diferenciadas entre o que vem a ser feminino e masculino. Nessa perspectiva, há uma imposição do sentido e do significado de feminilidade e masculinidade, com regras e padrões que estabelecem e indicam o comportamento dos indivíduos, assim como, o seu papel na sociedade, visando sempre à manutenção do sistema do capital.

Corroborando com isso, Haraway (2004) apresenta que gênero foi desenvolvido para contestar a naturalização da diferença sexual em diversas arenas de luta. Nessa mesma conjuntura, a autora supracitada ainda coloca que a teoria e a prática feminista em torno das questões que envolvem esse conceito, pretendem "explicar e transformar sistemas históricos de diferença sexual nos quais 'homens' e 'mulheres' são socialmente constituídos e posicionados em relações de hierarquia e antagonismo" (HARAWAY, 2004, p. 211).

Essas relações hierárquicas e antagônicas que a autora apresenta, fazem parte do engenhoso e complexo sistema social que vivemos, que é o sistema patriarcal-racista-capitalista (CISNE, 2018). Um sistema de dominação-exploração, inerente a lógica do capital; desigual e opressor, intrínseco ao patriarcado; discriminatório e prepotente, basilar do racismo.

Neste contexto social que está à escola, uma instituição que surge com a finalidade de repassar o saber historicamente acumulado pelos homens, além de atuar na subjetividade, influenciando os indivíduos para agirem desta ou daquela maneira (FRERES; RABELO; MENDES SEGUNDO, 2008). Não sendo a escola um campo neutro onde, após entrarmos, os conflitos sociais permanecem do lado de fora (GOMES, 1996), esta reflete os conflitos e as contradições existentes, reforçando, em muitas vezes, os preceitos estruturantes, conservadores e ultrapassados que constituem o contexto social vigente.

Vivemos em uma sociedade que a cada 2 minutos uma mulher é vítima por arma de fogo (RELÓGIOS DA VIOLÊNCIA, 2020); que desvaloriza o trabalho das mulheres, visto que estas, no estado do Rio Grande do Sul, têm salário 26\% menor que dos homens e queda nas posições de chefia (DIÁRIO DE CANOAS, 2020). Como se não bastasse, ainda somos campeões mundiais quando a questão é crime contra as minorias sexuais, dado que a cada 20 horas um LGBT+ morre de forma violenta vítima da LGBTfobia (RELATÓRIO GGB, 2019). 
Visto todo esse contexto social, político e escolar que vivemos, este estudo teve como proposta principal, averiguar o tratamento dado a temática gênero em escolas localizadas em um município do extremo sul do Brasil, assim como, identificar o posicionamento dos professores e professoras sobre a temática gênero ser trabalhada nessas instituições. Visando abarcar as questões de gênero, essa pesquisa, para além dos seus objetivos determinados, também teve por finalidade, promover a reflexão e o debate dessa temática no âmbito escolar, explorando e percebendo as múltiplas formas de ser homem e mulher.

\section{METODOLOGIA}

O presente estudo caracteriza-se como uma investigação qualitativa, visto que esta valoriza a compreensão dos processos e não apenas dos resultados, sobretudo incluindo o que é singular num contexto histórico e social mais ampliado (MINAYO; GUERRIERO, 2014). Concomitantemente a investigação qualitativa, foi realizado primeiramente um estudo exploratório, onde parte-se de uma hipótese e aprofunda-se seu estudo nos limites de uma realidade específica, buscando maiores conhecimentos para, em seguida, planejar uma pesquisa descritiva. Assim, posteriormente foi realizado o estudo descritivo, produzindo uma análise das características de fatos ou fenômenos, descrevendo o conhecimento assimilado, assim como as percepções dos sujeitos investigados.

As escolas participantes dessa pesquisa fazem parte da rede escolar municipal da cidade de Rio Grande ${ }^{1}$, sendo que esta rede fica aos cuidados da Secretaria Municipal de Educação (SMED). Com a finalidade de delimitar o campo de investigação, uma escola de cada distrito fez parte da pesquisa, totalizando assim cinco instituições participantes. Como critério de escolha, optou-se pelas maiores escolas em número de alunos - de cada distrito -, pretendendo alcançar uma maior abrangência do município.

Com o levantamento realizado, as escolas apresentadas no quadro abaixo foram às selecionadas em concordância com o critério estabelecido. Os dados expostos são básicos para uma visão geral das escolas investigadas, mas suficientes para a seleção requerida (Quadro 1):

Quadro 1 - Escolas selecionadas para o estudo.

\begin{tabular}{|c|c|c|c|}
\hline Escola & Distrito & $\begin{array}{c}\text { Número total de } \\
\text { alunos }\end{array}$ & $\begin{array}{c}\text { Número total de } \\
\text { professores de } \\
\text { Educação Física }\end{array}$ \\
\hline Helena Small & Rio Grande & 1095 & 4 \\
\hline Maria Angélica Villanova Leal Campello & Taim & 244 & 1 \\
\hline Cristovão Pereira de Abreu & Povo Novo & 120 & 1 \\
\hline
\end{tabular}

\footnotetext{
${ }^{1}$ Município localizado no extremo sul do Estado do Rio Grande do Sul, sendo o mais antigo do estado. De médio porte, a cidade de Rio Grande está dividida por cinco distritos, sendo eles: $1^{\circ}$ Distrito — Rio Grande; $2^{\circ}$ Distrito - Ilha dos Marinheiros; $3^{\circ}$ Distrito — Povo Novo; $4^{\circ}$ Distrito — Taim e o $5^{\circ}$ Distrito — Vila da Quinta.
} 


\begin{tabular}{|c|c|c|c|}
\hline Sylvia Centeno Xavier & $\begin{array}{c}\text { Ilha dos } \\
\text { Marinheiros }\end{array}$ & $\mathrm{xx}^{2}$ & 1 \\
\hline Coriolano Benício & $\begin{array}{c}\text { Vila da } \\
\text { Quinta }\end{array}$ & 475 & 1 \\
\hline
\end{tabular}

Fonte: Elaborado pelos autores.

Realizando contato com estas, apresentando documentação e expondo os objetivos e como seria desenvolvida a pesquisa dentro da instituição escolar, todas as escolas aceitaram o convite, disponibilizando os sujeitos para fazerem parte do estudo.

Estes, por sua vez, foram de dois grupos distintos: 1) professores e professoras de Educação Física; 2) alunos e alunas do $9^{\circ}$ ano do ensino fundamental; ambos de cada escola investigada. A escolha desses dois grupos de sujeitos justificou-se pelo fato de conseguirmos obter resultados satisfatórios frente à questão da investigação, com variados olhares sobre a instituição escolar e as questões de gênero. Ainda nessa lógica, o fato de ter optado por alunos e alunas do $9^{\circ}$ ano do ensino fundamental, ocorre por conta de estes e estas possuírem um maior tempo de Educação Física escolar, tendo assim, maiores subsídios para responder os questionamentos.

Apresentando um convite formal aos professores e professoras, assim como um termo de consentimento livre e esclarecido, dos sete professores e professoras possíveis, seis participaram, visto que uma professora estava com problemas pessoais, não conseguindo marcar um horário para a realização da entrevista. Dessa forma, o quadro de professores e professoras participantes ficou da seguinte forma (Quadro 2):

Quadro 2 - Caracterização dos professores e professoras participantes.

\begin{tabular}{|c|c|c|c|c|}
\hline $\begin{array}{c}\text { Professo } \\
\mathbf{r}\end{array}$ & $\begin{array}{c}\text { Idad } \\
\text { e }\end{array}$ & Gênero & Formação e gênero $^{3}$ & Carga horária \\
\hline A & 47 & $\mathrm{~F}$ & $\begin{array}{l}\text { Nenhuma formação relacionada a } \\
\text { gênero }\end{array}$ & $\begin{array}{l}\text { 20h - município; } 20 \mathrm{~h} \text { - } \\
\text { SINTERG }^{4}\end{array}$ \\
\hline B & 61 & $\mathrm{~F}$ & $\begin{array}{l}\text { Nenhuma formação relacionada a } \\
\text { gênero }\end{array}$ & 20h - município \\
\hline $\mathrm{C}$ & 28 & $\bar{F}$ & $\begin{array}{c}\text { Nenhuma formação relacionada a } \\
\text { gênero }\end{array}$ & $\begin{array}{c}\text { 20h - município de Rio Grande; } \\
\text { 20h - município de Pelotas }\end{array}$ \\
\hline $\mathrm{D}$ & 41 & $\mathrm{M}$ & $\begin{array}{l}\text { Nenhuma formação relacionada a } \\
\text { gênero }\end{array}$ & 20h - município \\
\hline $\bar{E}$ & 49 & $\bar{F}$ & $\begin{array}{c}\text { Nenhuma formação relacionada a } \\
\text { gênero }\end{array}$ & 20h-município; 20h - estado \\
\hline $\mathrm{F}$ & 60 & $\mathrm{M}$ & $\begin{array}{c}\text { Nenhuma formação relacionada a } \\
\text { gênero }\end{array}$ & 20h - município \\
\hline
\end{tabular}

Fonte: Elaborado pelos autores.

\footnotetext{
${ }^{2} \mathrm{O}$ número de alunos não estava atualizado no sistema da SMED, no entanto, é a única escola com professores de Educação Física desse distrito.

${ }^{3}$ Procuramos averiguar se os professores e as professoras tinham alguma formação relacionada a gênero, a fim de perceber se tinham um entendimento prévio da temática.

${ }^{4}$ Sindicato dos trabalhadores em educação de Rio Grande.
} 
Nas oito turmas de $9^{\circ}$ ano das cinco escolas participantes, a grande maioria dos alunos e alunas participou, havendo algumas recusas com motivos desconhecidos. Em um primeiro momento, juntamente com o professor/professora de Educação Física, a pesquisa foi explicada aos alunos e as alunas, sendo nesse momento entregue o termo de assentimento do menor aos que aceitaram participar, combinando, um dia e horário para a aplicação do questionário aos alunos e as alunas que entregassem o termo assinado.

Concretizada a entrega do termo e, consequentemente, aceitando o convite de participação na pesquisa, os números de participantes foram sendo fechados, assim como, a predominância de gênero 5 e idade (Quadro 3):

Quadro 3 - Caracterização dos alunos e alunas participantes.

\begin{tabular}{|c|c|c|c|c|}
\hline Escola & Idade & Feminino & Masculino & Total \\
\hline Coriolano Benício & $14-17$ anos & 3 & 7 & 10 \\
\hline Cristovão Pereira de Abreu & $14-15$ anos & 1 & 2 & 3 \\
\hline Sylvia Centeno Xavier & $14-18$ anos & 7 & 5 & 12 \\
\hline Maria Angélica Villanova Leal Campello & $14-19$ anos & 10 & 10 & 20 \\
\hline Helena Small & $14-17$ anos & 47 & 30 & 77 \\
\hline
\end{tabular}

Fonte: Elaborado pelos autores.

Com a finalidade de averiguação dos fatos, os instrumentos utilizados na coleta de dados, foram de dois tipos: as entrevistas semiestruturadas e o questionário.

As entrevistas visam à compreensão ampla do fenômeno que está sendo estudado, sendo que na pesquisa qualitativa todos os dados da realidade são importantes e devem ser examinados (GODOY, 1995). Nesse sentido, foi realizado um total de 06 entrevistas semiestruturadas com os professores e professoras, que, baseadas em um roteiro, englobava perguntas abertas e questionamentos básicos, onde, apoiados em hipóteses e/ou teorias, os participantes tiveram a possibilidade de discorrer sobre o tema proposto (BONI; QUARESMA, 2005).

Tendo um caráter de diálogo e sendo gravadas em aparelho de celular, as entrevistas foram realizadas no ambiente natural dos participantes, a escola, sempre de modo individual e com duração média de 30 minutos. Com a finalidade de direcionar a discussão para o assunto da pesquisa, algumas questões adicionais foram feitas, evitando também que os entrevistados e as entrevistadas tangenciassem o tema (BONI; QUARESMA, 2005).

Nos alunos e nas alunas, por sua vez, foram aplicados 122 questionários, sendo estes compostos por um conjunto de questões claras e objetivas, intencionando alcançar com êxito

\footnotetext{
${ }^{5}$ Nos questionários foi disponibilizado um espaço para os alunos e as alunas colocarem o seu gênero, sendo que somente os gêneros masculino e feminino foram apontados.
} 
respostas que auxiliassem no enriquecimento da pesquisa. Os/as participantes responderam os questionários com as suas próprias palavras, sem qualquer restrição, visto que foram aplicados na própria sala de aula, de modo coletivo/ individual (todos e todas estavam presentes no momento, mas cada um respondeu o seu questionário individualmente).

Todos os dados obtidos através desses instrumentos de coleta foram analisados a partir da Análise Textual Discursiva (ATD), visto que essa se configura como uma metodologia de etapas extremamente minuciosas, requerendo do pesquisador a atenção e a rigorosidade em cada etapa do processo (DAS NEVES PEDRUZZI et al., 2015). Assim, com a finalidade de categorizar os dados coletados, começamos pelos quatro focos distintos presente nesse método: 1) desmontagem dos dados, unitarização do corpus da pesquisa; 2) relação dos elementos, categorizando, o começo da sistematização; 3) nova compreensão de determinada realidade e 4) formação de um todo, um sistema auto - organizado (DAS NEVES PEDRUZZI et al., 2015). Logo, seguimos as etapas que constituem esses quatro focos: unitarização - o texto (respostas das entrevistas e dos questionários) foi desconstruído e fragmentando em unidades de significados; depois houve a organização de categorias, as quais foram constantemente reagrupadas, visando apresentar de maneira mais fidedigna os dados coletados; e, por fim, foram elaborados os metatextos, ou seja, a prática da escrita, sendo constantemente aperfeiçoados e reorganizados, sendo esta a característica central do processo de desenvolvimento desta metodologia (DAS NEVES PEDRUZZI et al., 2015).

Importante ressaltar que o presente estudo respeitou a Resolução 466/12 e os princípios éticos da pesquisa envolvendo seres humanos, (BRASIL, 2012), sendo aprovado pelo parecer $\mathrm{n}^{\circ}$ 3.098.884. Cabe ainda destacar, que durante a análise e escrita, com a finalidade de não identificar os/as participantes, utilizamos pseudônimos que traziam o tipo de atividade na escola seguida de uma letra: "Professora A", para professores e professoras, sendo que para os alunos e as alunas, visto a grande quantidade, foi também identificada à escola que fazia parte: "Aluno B - Escola Cristovão Pereira de Abreu".

\section{Escola, questões de gênero e sistema educacional: partindo da perspectiva da sociedade do capital}

Uma instituição social própria, a escola tem a sua sistematização ditada através de regras e normas, que almejam delimitar e organizar esse espaço institucional. Dentro desse local, há uma série de relações sociais e de poder entre os sujeitos, formando assim, uma trama própria daquela cultura escolar. 
Mesmo existindo em cada escola a sua própria cultura, no contexto da sociedade de classes, a educação que nas escolas é transmitida, repassa "valores, atitudes, comportamentos, conhecimentos a todos os indivíduos, mas com uma ressalva: essa transmissão é feita de acordo com os interesses da classe dominante" (FRERES; RABELO; MENDES SEGUNDO, 2008, p. 2). Assim, de acordo com esses interesses, há uma grande diferença entre o que cada classe deve aprender:

Enquanto os filhos da classe dominante se preparavam para serem os futuros dirigentes da sociedade, os filhos dos trabalhadores tiveram acesso ao conhecimento básico necessário à produção, habilitando-se profissionalmente para a execução de tarefas laborativas (FRERES; RABELO; MENDES SEGUNDO, 2008, p. 2).

Nessa conjuntura, entendemos que "somente numa sociedade emancipada todo o sistema educacional será modificado para a reprodução social sem interesses de classes" (FRERES; RABELO; MENDES SEGUNDO, 2008, p. 9). Isso porque, percebemos que:

Sob a lógica do capital, não há a menor possibilidade de realização de uma educação emancipadora, visto que ela, tendo esse sistema como base, necessariamente contribuirá para a disseminação dos interesses da classe dominante, bem como dos saberes que ela necessita para a produção (FRERES; RABELO; MENDES SEGUNDO, 2008, p. 9).

Assim, a escola espelha essa sociedade de classes, trazendo conceitos, problemáticas e naturalizações que existem para além dos muros da escola. Nesse sentido, nota-se que a escola não é um campo neutro onde, após entrarmos, os conflitos sociais permanecem do lado de fora. Ela é um espaço sociocultural onde convivem os conflitos e as contradições (GOMES, 1996). Corroborando com isso, a professora A colocou a sua posição:

[...] a escola tá ainda muito presa a questões assim, não é todo o professor que superou o machismo... (Entrevista Professora A).

Além de refletir a sociedade, a escola também internaliza preceitos estruturantes da sociedade patriarcal, racista e capitalista, adotando medidas que naturalizam situações, que aumentam a segregação entre os indivíduos e que corroboram com a opressão. Ela assume direcionamentos diferentes em cada momento histórico, atendendo, historicamente, e de forma eficaz aos interesses do capital (FRERES; RABELO; MENDES SEGUNDO, 2008).

E como ficam as questões de gênero nesse espaço? Ou não ficam?

Por um lado, temos escolas que ainda são muito resistentes em abordar essa temática. Do Amaral Madureira e Branco (2015), apresentam que temos uma deficiência em relação à formação dos professores e professoras diante dessa temática, necessitando assim de atividades de 
capacitação dos mesmos e das mesmas. Trazendo outra justificativa, o estudo de Maia; Navarro e Maia (2011), apresentam que a crença de que as diferenças entre homens e mulheres são universais e imutáveis reforçam uma postura omissa ou reprodutivista do professor e da professora, resultando em uma instituição escolar que negligencia o seu importante papel político de instrumento de modificação social.

Por outro lado, temos escolas que são abertas para implantação de programas e projetos que tratem sobre esse tema, escolas que constroem junto à comunidade escolar, atividades que trabalhem didaticamente sobre as desigualdades existentes, problematizando e questionando o porquê de ainda vivermos em uma sociedade patriarcal, racista e capitalista. Exemplificando isso, temos o projeto "Escola Promotora da Igualdade de Gênero" que atua em diversas escolas do município desta pesquisa, buscando nas diversas atividades, problematizar as desigualdades de gênero e sexuais, contribuindo, assim, para a inserção e participação igualitária em direitos e deveres de mulheres e homens na sociedade (GESE, n.d.).

Refletindo essa sociedade sexista, as opressões de gênero permeiam o espaço da maioria das escolas, visto que diferentes mecanismos são utilizados pelas instituições escolares. Por um momento dissemina conteúdos e metodologias diferenciados para mulheres e homens, se utilizando de preceitos estruturantes da sociedade patriarcal. Por outro caracteriza sexualmente os gestos, impondo papéis que reforcem e/ou produzam os sentidos de fragilidade feminina e de racionalidade masculina, colaborando, assim, no binarismo sexista existente (WERNECK, 1996).

Ainda sobre isso, os dados da "Pesquisa nacional sobre o ambiente educacional no Brasil (2016)", ressalta as opressões de gênero existentes nas instituições educacionais, principalmente as relacionadas às camadas não heteronormativas:

1) Perguntamos se em algum momento no último ano letivo se sentiram inseguros/as na instituição educacional por causa de alguma característica pessoal, incluindo: orientação sexual, gênero, identidade/expressão de gênero (ou seja, em termos tradicionais, até que ponto a aparência ou os comportamentos correspondiam a noções tradicionais do "masculino" ou do "feminino"), bem como o tamanho ou o peso corporal.

Muitos/as dos/das estudantes LGBT se sentiam inseguros/as na instituição educacional por causa de sua orientação sexual e identidade / expressão de gênero:

- $60,2 \%$ afirmaram se sentir inseguros/as na instituição educacional no último ano por causa de sua orientação sexual;

- $42,8 \%$ se sentiam inseguros/as por causa da maneira como expressavam o gênero (PESQUISA NACIONAL SOBRE O AMBIENTE EDUCACIONAL NO BRASIL, 2016, p. 27).

2) Perguntamos para os/as estudantes sobre a frequência com que ouviam comentários LGBTfóbicos: 
- Quase a metade $(47,5 \%)$ dos/das estudantes LGBT relataram ter ouvido outros/as estudantes fazendo comentários pejorativos, tais como "bicha," "sapatão," ou "viado," frequentemente ou quase sempre na instituição educacional. Além disso, perguntamos para os/as estudantes que costumavam ouvir comentários LGBTfóbicos na instituição educacional até que ponto isto estava comum entre a população estudantil;

- $(21,7 \%)$ relataram que esses tipos de comentários eram feitos pela maioria dos seus pares;

- Mais de dois terços $(69,1 \%)$ dos/das estudantes relataram que já ouviram comentários LGBTfóbicos feitos por professores/as ou outros/as funcionários/as da instituição educacional (PESQUISA NACIONAL SOBRE O AMBIENTE EDUCACIONAL NO BRASIL, 2016, p. 31).

E como todas as situações sempre podem piorar, uma série de políticas retrógradas estão pairando sobre o sistema educacional brasileiro. Amordaçando a liberdade de ensinar, o programa Escola sem Partido surgiu com a proposta de restringir a liberdade de expressão dos professores e das professoras, ditando uma série de regras, que estão expostas na figura a seguir (Figura 1):

Figura 1 - "Regras" do professor

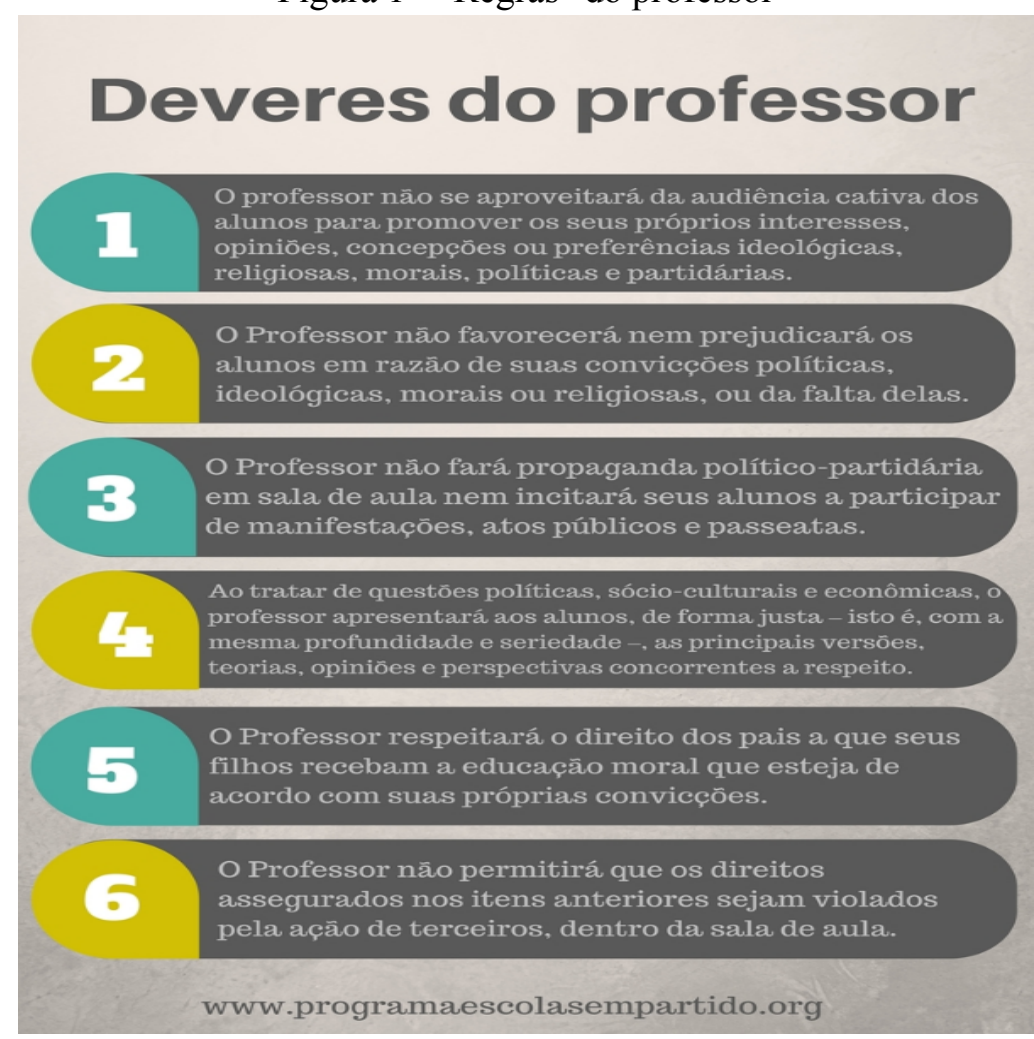

Fonte: Site do programa: https://www.programaescolasempartido.org/

Documentos que determinam diretrizes, metas e estratégias para a educação, caminham conjuntamente com o programa já citado, sendo também políticas educacionais consideradas retrógradas. Em 2017, o Conselho Nacional de Educação (CNE) acatando aos pedidos do 
Ministério da Educação (MEC) retirou da Base Nacional Comum Curricular (BNCC), as menções a gênero e sexualidade, incluindo o eixo "princípios e valores éticos" e o ensino religioso. Com uma forte bancada religiosa, os parlamentares do congresso foram maioria na votação, igualando a BNCC ao Plano Nacional de Educação (PNE), que também não menciona as questões de gênero em sua última versão documental.

Corroborando com isso, apresentamos a fala de uma das professoras participantes da pesquisa, uma fala que somente garante (infelizmente) o sucesso alcançado dessas políticas retrógradas:

Só que tão colocando dúvidas sobre o que a gente faz... No sentido de que a gente não deveria falar sobre isso, que a escola não deveria tratar sobre a sexualidade, que a escola não deveria tratar certos tabus... Mas se a gente não tratar. Quem vai? Vai ser essa influência que eles estão tendo desses outros meios... Vai ser a influencia da igreja... Vai ser influência da família... Tudo tinha que influência-los... Mas não dizer que a escola não podia discutir isso... Só que existe uma frente nos últimos anos, não sei se da família ou de quem... Colocando em dúvida como a gente trabalha esse tema. Não pode ensinar que tem a camisinha, não pode dizer que existe diferentes sexualidades... Sim, mas a gente tá sendo questionado que não compete... Não teria competência nossa fazer isso... Eu acho um absurdo, porque que a escola não pode fazer? Como é... Então a gente tá direcionando a sexualidade da criança, não... A gente tá orientando elas saber sobre o assunto, agora que direção ela vai tomar, não foi por nossa influência... Eu acho que conhecimento nunca é demais. (Entrevista Professora E).

\section{As questões de gênero nas escolas Rio-Grandinas}

Diante de todo esse cenário apresentado no tópico anterior, procurou-se verificar nas escolas pesquisadas se as questões de gênero eram tratadas de alguma forma, seja através de programas, projetos e atividades afins. Três professoras afirmaram que em suas escolas não há nenhum tipo de atividade relacionada às questões que envolvem a temática de gênero. Já outro professor afirmou que apenas a professora da disciplina de religião trabalhou com a temática na escola, sendo que outra professora disse que em sua escola apenas no Projeto Político Pedagógico (PPP), há essa discussão. Apenas um professor acredita que sempre há esse debate nas instituições escolares.

Esses dados mostram que a maioria das instituições escolares participantes dessa pesquisa não trabalha com essa atual e pertinente temática. Importante entendermos que é preciso trabalhar com conteúdos contemporâneos, ou seja, com problemáticas dos nossos tempos atuais, garantindo aos alunos e as alunas o conhecimento do que de mais moderno existe no mundo, mantendo-o informado dos acontecimentos nacionais e internacionais, bem como do avanço da ciência e da técnica (COLETIVO DE AUTORES, 1992). 
Ainda nesse contexto, foi questionado qual o posicionamento dos professores e das professoras diante desse tipo de discussão nas escolas, resultando em dois grupos distintos, os que podemos chamar de pró-discussão e os contra a discussão:

[...] eu acho que dá muito resultado, tanto para a formação do professor [...] Bem positivo (Entrevista Professora A).

$\mathrm{Eu}$ acho que interessante né, um espaço para discutir e colocar essas questões [...] Porque eu acho que todo lugar é lugar, né? Mas, eu acho que é importante sim, se tiver algum projeto, seria interessante... (Entrevista Professora B).

$\mathrm{Eu}$ acho legal, eu acho interessante [...] acho importante. Esses grupos poderiam trabalhar mais, não sei se trabalham em alguma escola, mas aqui eu nunca vi nada nesse sentido... (Entrevista Professora C).

[...] eu acho que as crianças têm que vivenciar a discussão. A escola tem que ser um lugar para discutir e saber o correto... O correto quando eu digo é aquela coisa assim... Que não é o vulgar, que não é o banal, é o lado da ciência mesmo... O quê que é tu gerir uma criança? O quê que é tu cuidar de uma criança? Quê que é tu começar a se interessar pelo... Por outra pessoa... Independente agora do gênero. Ah porque eu sou bissexual... Poh, mas tu tens ideia o que são esses conceitos para ti tá... Ou é um modismo? Eu até tem horas... Penso que é um modismo... Só que o que está influenciando esse pensar desses alunos... Não é a escola, mas é alguma coisa fora, então eu acho que a escola tem que discutir... (Entrevista Professora E).

$\mathrm{Eu}$ acho que os projetos são importantes, todos os projetos, todos eles são importantes, entendesse... Só que a gente não vê os resultados na verdade, porque o projeto é lançado, desenvolvido... O quê que aconteceu? (Entrevista Professor F).

Percebemos que estas professoras e este professor entendem a importância que há em trabalhar as questões de gênero no âmbito escolar, sendo que algumas mostram os seus argumentos e problematizam o porquê de projetos não serem aplicados na escola. O Coletivo de Autores (1992) reforça esse entendimento quando coloca que é preciso tratar de conteúdos que viabilize a leitura da realidade estabelecendo laços concretos com projetos políticos de mudanças sociais.

No grupo contra a discussão temos um professor:

[...] eu acho [...] que é uma coisa complicada né [...] eu acho que nada pode ser forçado ou abusivo demais, eu digo para os meus alunos assim ó, não é porque hoje está mais liberada essa questão toda que tu pode fazer o que tu queres, eu digo assim ó, eu já não acho certo casal dito normal né, ficar se beijando na frente de todo mundo [...] então não posso achar correto [...] Não, normal não é (Entrevista Professor D).

Ele acredita que trabalhar com esse assunto na instituição escolar é um tanto complexo, que “caberia mais a família orientar” (Entrevista Professor D). Nesse contexto, uma pesquisa realizada com pessoas entre 15 e 25 anos, aponta que a família não é nem a segunda opção quando os/as 
jovens precisam tirar dúvidas sobre sexo e temas afins: $60 \%$ deles buscam a internet, 15\%, os amigos, e somente $8 \%$ recorrem aos pais (CORREIO BRAZILIENSE, 2017).

Seria interessante se as famílias realmente conversassem, orientassem as suas crianças e jovens. No entanto, na maioria dos lares - como aponta a pesquisa - o que ainda encontramos é um grande tabu, um silenciamento dentro do núcleo familiar quando o assunto é gênero e sexualidade, como se essas questões não fossem inerentes aos seres humanos.

Por outro lado, podemos perceber esse silenciamento como uma forma de educar. A maioria das crianças e jovens vê as questões que envolvem gênero e sexualidade como um tabu. Com isso, eles crescem pensando nesse tema, mais precisamente no sexo, como algo proibido e promíscuo, não conhecendo assim o seu corpo e os seus desejos.

A educação sexual no âmbito familiar também pode ser baseada no sistema patriarcal de dominação-exploração que vivemos. Seguindo esse propósito, os homens (meninos) acessam informações em diversas mídias que reforçam a objetificação das mulheres, fortalecendo relações que se pautam a partir disso, além de substanciar ainda mais o papel de submissão que a elas foi colocado. A questão da masturbação é bem distinta entre homens e mulheres, visto que eles são "liberados" para isto, sendo essas situações extremamente proibidas a elas. Ainda nessa lógica, a organização familiar no que tange os deveres de homens e mulheres, não é criticada, muito menos repensada: as mulheres/mães são sobrecarregadas de afazeres domésticos, as filhas são as suas ajudantes e os homens e os filhos não fazem nada, pois lhes foi dito que esse é o seu papel social: detentor do poder, tendo liberdade para fazer escolhas (SAFFIOTI, 1987).

Ainda no viés da educação sexual baseada no sistema patriarcal, temos a questão da violência doméstica, contra crianças e mulheres. Em muitos lares a agressão é considerada normal, fazendo parte do cotidiano de muitas famílias, tendo como principais vítimas crianças e mulheres. Nesse ambiente, são grandes as probabilidades das crianças sofrerem de depressão, ansiedade, transtornos de conduta e atrasos no seu desenvolvimento cognitivo, (CASIQUE; FUREGATO, 2006). Além do mais, essa violência auxilia no desenvolvimento da conduta entre os sexos, pois é bastante provável a reprodução dessa mesma lógica na vida adulta, visto que o resultado é a formação de futuros agressores, influenciando assim no desenvolvimento da criança e do (da) jovem.

Diante de todo esse cenário, fica a pergunta: e quem educa/educou essas famílias? Por influência de uma sociedade que silencia tudo que envolve sexo, as famílias sentem vergonha de falar sobre e, em alguns casos, não se sentem aptos para orientar, visto que talvez nem tenham tido esse tipo de conversa com seus próprios pais (SAVEGNAGO; ARPINI, 2013). Corroborando com isso, Brandão (2004) apresenta que as conversas que ocorrem sobre sexualidade na família "tomam 
formas indiretas, pouco palpáveis, permeadas de reticências, advertências, reprimendas" (p. 80), visto que essas não são baseadas no adolescente em si, mas em fatores externos, como na experiência de outras pessoas, em reportagens, filmes, ou seja, no padrão histórico-cultural construído de sociedade patriarcal que vivemos (SAVEGNAGO; ARPINI, 2013).

Visto esse tipo de sociedade que estamos inseridos e a dificuldade de discussão da temática e afins dentro do núcleo base que é o familiar, perguntamos aos alunos e alunas participantes da pesquisa se, primeiramente, já haviam feito parte de algum projeto (Figura 2), e, secundariamente, a temática do projeto, com a finalidade de perceber se as questões que envolvem gênero faziam parte desse repertório:

Figura 2: Participação dos alunos e das alunas em algum projeto na escola.

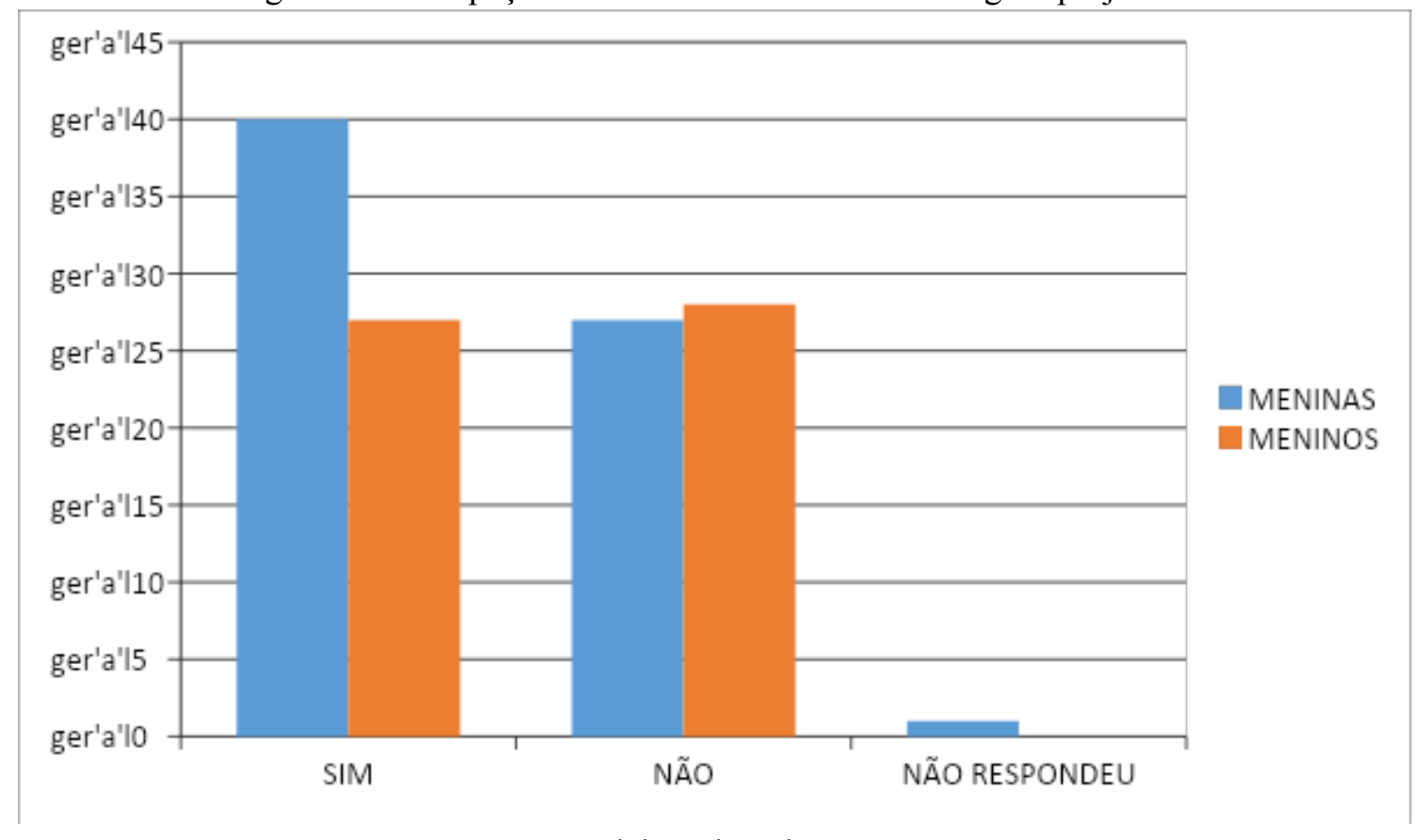

Fonte: Elaborado pelos autores

Conforme mostra a figura $2,54 \%$ dos participantes da pesquisa, independente do gênero, já participaram de projetos na escola, sendo que desses são 40 meninas e 27 meninos. Em contrapartida, 45\% (27 meninas e 28 meninos) afirmou que nunca participou de projetos na escola, sendo que apenas uma menina não respondeu essa questão.

Desse modo, como já dito, com a intenção de aprofundar a compreensão da realidade escolar, os alunos e alunas citaram os projetos que já haviam participado, sendo que foram mencionados os seguintes: teatro; dança; escola com vida; olimpíadas, escrita; torneio de futebol; vôlei; mulher e violência; feira de ciências; na área de nutrição e saúde de jogadores; mais educação; Helenart; banda escolar; criação e vídeos; filmes; técnicas circenses; música; passeio 
ciclístico; leitura; gincana, rústica, águas do Rio Grande, livro sobre a África; coreografia; sarau; contra o bulling e preconceito; saídas de campo; outubro rosa; Centro de Tradições Gaúchas (CTG); xadrez; mulheres do Helena; importância das mulheres na sociedade.

Dentre todos os projetos citados, cinco (marcados em negrito) estão, de alguma forma, ligados com as questões de gênero. Visto termos um misto de tipos de temáticas e, consequentemente, de tipos de aprendizagens, temos um número interessante de projetos que trabalharam as questões de gênero. Não podemos constatar se esses projetos ainda continuam, quanto tempo durou e qual o objetivo geral desses, mas podemos notar que foi uma, dentre as muitas, maneira de trabalhar essa temática no ambiente escolar.

Também ponderando sobre, algumas professoras entrevistadas citaram um projeto que tem grande atuação no município pesquisado:

Mas tem o GESE, que na FURG, eles trabalham bem forte assim, as questões de gênero (Entrevista Professora A).

A FURG, junto com o CEAMECIM, tinha um projeto sobre sexualidade, questões de gênero aqui (Entrevista Professora E).

Denominado "Escola Promotora da Igualdade de Gênero", este é um projeto que foi criado pelo Grupo de Pesquisa Sexualidade e Escola (GESE) ${ }^{6}$, da Universidade Federal do Rio Grande (FURG), e que atua em inúmeras escolas do município de Rio Grande - RS, tendo por finalidade:

[...] apoiar as escolas das redes estadual e municipal da Educação Básica do Rio Grande/RS que tenham interesse em desenvolver ações para a promoção e a reflexão acerca da igualdade e equidade dos gêneros (GESE, n. d.).

Diante disso, é de suma importância a inserção desses projetos nas instituições escolares. Confrontar as políticas, superando esse conservadorismo que está tentando se firmar, é um dos motivos de inserção dessas ações nas escolas. Além disso, importante que essas ações visem à equidade com vistas à construção de estratégias que resultem na redução dos indicadores de desigualdades, ao mesmo tempo, em que busquem dar visibilidade ao tema, sendo uma fundamental ferramenta na superação dessa problemática situação (GESE, n. d.).

\section{CONSIDERAÇÕES FINAIS}

No que diz respeito ao âmbito escolar e as questões de gênero, essa pesquisa confirma o que outros estudos já haviam ponderado, sobre essa instituição não ser um campo neutro, pois os

\footnotetext{
${ }^{6} \mathrm{O}$ grupo tem buscado ao longo dos anos, problematizar as desigualdades sexuais e de gêneros; estimular a criticidade, a curiosidade e a criatividade; valorizar o convívio social e o pluralismo além de contribuir para uma sociedade mais justa e igualitária, que respeite e valorize as diferenças entre os sujeitos (Fonte: GESE, n. d).
} 
conflitos e as contradições existentes na sociedade, também lá existem. Além disso, ela ainda é um espaço que internaliza os preceitos que estruturam a sociedade, reforçando binarismos, naturalizando situações. Conforme foram ressaltados, os objetivos de políticas retrógradas que pairam pelo sistema educacional brasileiro, alcançam as instituições escolares, influenciando na metodologia, nos conteúdos, nas aprendizagens, assim como, no modo de se portar dos professores e professoras.

Ainda neste contexto, identificamos que, segundo apresentou a maioria dos participantes, embora tenham sido discutidas através de projetos dispostos para os alunos e alunas, às questões que envolvem gênero não são uma temática muito recorrente nas escolas, não havendo muitas atividades que tratem e discutem sobre esta. Nesse sentido, quando buscamos compreender as percepções dos professores e professoras acerca dessa temática ser tratada nas escolas e também nas aulas de Educação Física, encontramos dois grupos distintos: os pró-discussão - sendo os que entendem a importância que há em trabalhar as questões de gênero no âmbito escolar; e os contra discussão - consistindo, nos que acreditam que debater esse tema na escola é muito complexo, pois poderíamos direcionar de uma maneira equivocada, cabendo mais a família orientar.

Desse modo, podemos concluir que os professores e as professoras participantes dessa pesquisa têm maneiras distintas de enxergar o mundo e a sociedade que vivemos. Acreditar que a temática gênero é pertinente de discussão no âmbito escolar, revela o seu pensamento inverso ao que é imposto, além de mostrar o quão alinhado está o pensamento à busca pela transformação radical do contexto social. Por outro lado, temos os que não apresentam interesse nessa discussão, não abrindo espaço para o debate em uma instituição tão importante como a escola, revelando o quão interessado está na manutenção da ordem social da lógica do sistema de dominação-exploração.

Por fim, destacamos que não cabe nesse artigo trazer soluções para a problemática que envolve gênero e o âmbito escolar, no entanto, consideramos necessária ressaltar sugestões que podem auxiliar no enfrentamento dessa situação. Quanto ao professor/a, seria interessante que ele/a repense a sua prática de ensino; suas ações; treinando a escuta; abrindo-se para o diálogo real. Quanto a instituição escolar, é emergente que a mesma coloque como elemento central a promoção dos direitos humanos; identificando, prevenindo e enfrentando situações de preconceito; rediscutindo normas e currículos; reconhecendo as diferenças e a diversidade. Com isso, acreditamos que o primeiro passo já será dado, almejando a transformação do nosso contexto social. 


\section{REFERÊNCIAS}

BONI, Valdete; QUARESMA, Sílvia Jurema. Aprendendo a entrevistar: como fazer entrevistas em Ciências Sociais. Em Tese, v. 2, n. 1, p. 68-80, 2005. Disponível em:

https://periodicos.ufsc.br/index.php/emtese/article/view/18027/16976 Acesso em: 27 de abril de 2021.

BRASIL. Ministério da saúde; conselho nacional de saúde. Resolução n. 466, de 12 de dezembro de 2012. Aprova diretrizes e normas regulamentadoras de pesquisas envolvendo seres humanos. Brasília, Diário Oficial da União, 12 dez. 2012.

CASIQUE, Leticia Casique; FUREGATO, Antônia Regina Ferreira. Violência contra mulheres: reflexões teóricas. Revista Latino-Americana de Enfermagem, v. 14, n. 6, 2006. Disponível em: https://www.redalyc.org/pdf/2814/281421865018.pdf Acesso em: 27 de abril de 2021.

CISNE, Mirla. Feminismo e marxismo: apontamentos teórico-políticos para o enfrentamento das desigualdades sociais. Serviço Social \& Sociedade, n. 132, p. 211-230, 2018. Disponível em: https://www.scielo.br/pdf/sssoc/n132/0101-6628-sssoc-132-0211.pdf Acesso em: 27 de abril de 2021.

CORREIO BRAZILIENSE. Educação (sexual) vem de casa? 2017. Disponível em:

https://www.correiobraziliense.com.br/app/noticia/revista/2017/10/22/interna revista correio,634722/educac ao-sexual-vem-de-casa.shtml. Acesso em: 13 de abril de 2021.

DAS NEVES PEDRUZZI, Alana et al. Análise textual discursiva: os movimentos da metodologia de pesquisa. Atos de pesquisa em Educação, v. 10, n. 2, p. 584-604, 2015. Disponível em:

https://bu.furb.br/ojs/index.php/atosdepesquisa/article/view/4312/3060 Acesso em: 27 de abril de 2021.

DIÁRIO DE CANOAS. No RS, mulheres têm salário $26 \%$ menor que dos homens e queda nas posições de chefia, 2020. Disponível em:

http://www.diariodecanoas.com.br/noticias/rio grande do sul/2020/03/05/no-rs--mulheres-tem-salario-26-menor-que-dos-homens-e-queda-nas-posicoes-de-chefia.html. Acesso em: 15 de março de 2021.

DO AMARAL MADUREIRA, Ana Flávia; BRANCO, Ângela Uchoa. Gênero, sexualidade e diversidade na escola a partir da perspectiva de professores/as. Temas em Psicologia, v. 23, n. 3, p. 577-591, 2015.

Disponível em: https://www.redalyc.org/pdf/5137/513751492005.pdf Acesso em: 27 de abril de 2021.

FRERES, Helena; RABELO, Jackeline; MENDES SEGUNDO, M. O papel da educação na sociedade capitalista: uma análise onto-histórica. In: CONGRESSO BRASILEIRO DE HISTÓRIA DA

EDUCAÇÃO. 2008. p. 1-15. Disponível em:

https://silo.tips/download/o-papel-da-educaao-na-sociedade-capitalista-uma-analise-onto-historica-1 Acesso em: 27 de abril de 2021.

GESE. Sexualidade e Escola - Escolas Promotoras da Igualdade de Gênero. Disponível em: http://www.sexualidadeescola.furg.br/index.php/igualdade-de-genero. Acesso em: 25 de fevereiro de 2021.

GODOY, Arilda Schmidt. Introdução à pesquisa qualitativa e suas possibilidades. RAE-revista de administração de empresas, v. 35, n. 2, p. 57-63, 1995. Disponível em:

https://www.scielo.br/pdf/rae/v35n2/a08v35n2.pdf Acesso em: 27 de abril de 2021.

GOMES, Nilma Lino. Educação, raça e gênero: relações imersas na alteridade. Cadernos Pagu, n. 6/7, p. 67-82, 1996. Disponível em:

https://periodicos.sbu.unicamp.br/ojs/index.php/cadpagu/article/view/1862/1983 Acesso em: 27 de abril de 2021. 
HARAWAY, Donna. " Gênero" para um dicionário marxista: a política sexual de uma palavra. Cadernos Pagu, n. 22, p. 201-246, 2004. Disponível em: https://www.scielo.br/pdf/cpa/n22/n22a09.pdf Acesso em: 27 de abril de 2021.

MAIA, Ana Claudia Bortolozzi; NAVARRO, Carolina; MAIA, Ari Fernando. Relações entre gênero e escola no discurso de professoras do ensino fundamental. Psicologia da Educação. Programa de Estudos

Pós-Graduados em Educação: Psicologia da Educação. ISSN 2175-3520, n. 32, 2011. Disponível em: https://revistas.pucsp.br/index.php/psicoeduca/article/view/39178/26535 Acesso em: 27 de abril de 2021.

METODOLOGIA, DO ENSINO DE EDUCAÇÃO FÍSICA. Coletivo de autores-São Paulo. 1992.

MINAYO, Maria Cecília de Souza; GUERRIERO, Iara Coelho Zito. Reflexividade como éthos da pesquisa qualitativa. Ciência \& Saúde Coletiva, v. 19, p. 1103-1112, 2014. Disponível em:

https://www.scielosp.org/article/csc/2014.v19n4/1103-1112/pt/ Acesso em: 27 de abril de 2021.

PESQUISA NACIONAL SOBRE O AMBIENTE EDUCACIONAL NO BRASIL (2016). Disponível em: http://static.congressoemfoco.uol.com.br/2016/08/IAE-Brasil-Web-3-1.pdf. Acesso em: 22 de fevereiro de 2021.

RELATÓRIO GRUPO GAY DA BAHIA, 2019. Disponível em: https:/grupogaydabahia.files.wordpress.com/2019/01/relat\%C3\%B3rio-de-crimes-contra-lgbt-brasil-2018-gr upo-gay-da-bahia.pdf Acesso em: 14 de fevereiro de 2021.

RELÓGIOS DA VIOLÊNCIA, 2020. Disponível em: https://www.relogiosdaviolencia.com.br/. Acesso em: 15 de abril de 2021.

SAFFIOTI, Heleieth Iara Bongiovani. O poder do macho. Editora Moderna, 1987.

SAVEGNAGO, Sabrina Dal Ongaro; ARPINI, Dorian Mônica. Conversando sobre sexualidad en la familia: miradas de niñas de grupos populares. Cadernos de Pesquisa, v. 43, n. 150, p. 924-947, 2013. Disponível em: https://www.scielo.br/pdf/cp/v43n150/10.pdf Acesso em: 27 de abril de 2021.

WERNECK, Christianne Luce Gomes. Dissimulação do uso social e político do corpo na Educação Física. In: Coletânea. $3^{\circ}$ Congresso Latino-Americano de Esporte, Educação e Saúde no movimento humano. Cascavel: Gráfica Universitária. 1996. p. 139-149.

\section{NOTAS DE AUTOR}

\section{AGRADECIMENTOS}

Agradecemos a Secretaria Municipal de Educação do município de Rio Grande - RS, as equipes diretivas das escolas, assim como, os sujeitos participantes pela grande colaboração nessa pesquisa. Agradecemos também a Coordenação de Aperfeiçoamento de Pessoal de Nível Superior - CAPES pela bolsa concedida.

CONTRIBUIÇÃO DE AUTORIA - Não se aplica.

\section{FINANCIAMENTO}

Coordenação de Aperfeiçoamento de Pessoal de Nível Superior - CAPES - bolsa.

CONSENTIMENTO DE USO DE IMAGEM - Não se aplica. 


\section{APROVAÇÃO DE COMITÊ DE ÉTICA EM PESQUISA}

Essa pesquisa teve aprovação do Comitê de Ética e Pesquisa - CEP da Universidade Federal de Pelotas - UFPEL, através da Plataforma Brasil e aprovada pelo parecer nº 3.098.884 de 20/12/2018.

CONFLITO DE INTERESSES - Declaramos que não há conflitos de interesse.

\section{LICENÇA DE USO}

Os autores cedem à Motrivivência - ISSN 2175-8042 os direitos exclusivos de primeira publicação, com o trabalho simultaneamente licenciado sob a Licença Creative Commons Attribution Non-Comercial ShareAlike (CC BY-NC SA) 4.0 International. Esta licença permite que terceiros remixem, adaptem e criem a partir do trabalho publicado, desde que para fins não comerciais, atribuindo o devido crédito de autoria e publicação inicial neste periódico desde que adotem a mesma licença, compartilhar igual. Os autores têm autorização para assumir contratos adicionais separadamente, para distribuição não exclusiva da versão do trabalho publicada neste periódico (ex.: publicar em repositório institucional, em site pessoal, publicar uma tradução, ou como capítulo de livro), com reconhecimento de autoria e publicação inicial neste periódico, desde que para fins não comerciais e compartilhar com a mesma licença.

PUBLISHER - uso exclusivo da revista

Universidade Federal de Santa Catarina. Programa de Pós-Graduação em Educação Física. LaboMídia - Laboratório e Observatório da Mídia Esportiva. Publicado no Portal de Periódicos UFSC. As ideias expressadas neste artigo são de responsabilidade de seus autores, não representando, necessariamente, a opinião dos editores ou da universidade.

\section{EDITORES}

Mauricio Roberto da Silva, Giovani De Lorenzi Pires, Rogério Santos Pereira.

\section{EDITOR DE SEÇÃO}

Juliano Silveira.

\section{REVISÃO DO MANUSCRITO E METADADOS}

João Caetano Prates Rocha; Keli Barreto.

\section{HISTÓRICO}

Recebido em: 13 de novembro de 2020.

Aprovado em: 18 de março de 2021. 